\title{
Contribution of the Tourniquet in the Prevention of Haemorrhages during Myomectomies at the University Hospital of Brazzaville
}

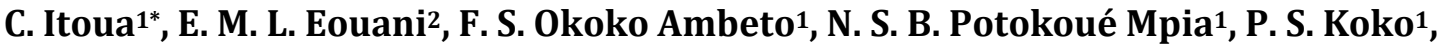 \\ F. O. Atipo-Tsiba Galiba ${ }^{3}$, L. H. Iloki ${ }^{1}$
}

${ }^{1}$ Obstetrics Gynaecology Department, University Hospital of Brazzaville, Brazzaville, Congo

${ }^{2}$ Obstetrics Gynaecology Department, Loandjili General Hospital, Pointe Noire, Congo

${ }^{3}$ Clinical Haematology Department, University Hospital Brazzaville, Brazzaville, Congo

Email: *clautairei@yahoo.com

How to cite this paper: Itoua, C., Eouani, E.M.L., Okoko Ambeto, F.S., Potokoué Mpia, N.S.B., Koko, P.S., Atipo-Tsiba Galiba, F.O. and Iloki, L.H. (2018) Contribution of the Tourniquet in the Prevention of Haemorrhages during Myomectomies at the University Hospital of Brazzaville. Open Journal of Obstetrics and Gynecology, 8, 701-706.

https://doi.org/10.4236/ojog.2018.88074

Received: March 30, 2018

Accepted: July 2, 2018

Published: July 5, 2018

Copyright $\odot 2018$ by authors and Scientific Research Publishing Inc. This work is licensed under the Creative Commons Attribution International License (CC BY 4.0).

http://creativecommons.org/licenses/by/4.0/

\section{(c) (i) Open Access}

\begin{abstract}
Objective: To check the effectiveness of tourniquet in the prevention of haemorrhage during myomectomies at the University Hospital of Brazzaville. Patients and methods: Analytical cross-sectional study, conducted at the University Hospital of Brazzaville from June 1, 2014 to June 30, 2016. Recruitment was performed by randomly matching each case of myomectomy performed using a tourniquet with two cases of myomectomy without tourniquet (50 cases vs 100 witnesses). We used as a tourniquet, the surgical glove knotted and tightened sufficiently at the level of the isthmus of the uterus to temporarily occlude the uterine arteries to ensure haemostasis lasting no more than one hour. Results: The mean age of the patients was similar in both groups $(36,1 \pm 2.2$ years vs $36.2 \pm 1.9$ years, $\mathrm{P}>0.05)$. Menorrhagia was the most common indication of myomectomy in both groups $(76 \%$ vs. $78 \% \mathrm{P}>$ 0.05). The mean haemoglobin level of the patients before the myomectomies was $9.03 \pm 1.10 \mathrm{~g} / \mathrm{dl}$ vs $9,75 \pm 1.29 \mathrm{~g} / \mathrm{dl}$; $\mathrm{P}>0.05$. Intraoperative uterine features were similar in size (18 weeks gestation, $14-24)$ and number of myomas (5 vs $4, \mathrm{P}>0.05$ ) in both groups. Polymyomectomy was more common in both groups ( $76 \%$ vs $73 \%, P>0.05$ ). Blood loss was reduced in the tourniquet group $(90.5 \pm 4.6 \mathrm{ml}$ vs $200.4 \pm 5.6 \mathrm{ml} ; \mathrm{P}<0.05)$, as well as the use of blood transfusion $(8 \%$ vs $50 \%, \mathrm{P}<0.05)$. Use of the number of sutures was reduced in the group with tourniquet $(3 \pm 0.2$ vs $6 \pm 0.2 \mathrm{P}<0.05)$. The duration of the procedure was shorter in the group with tourniquet $(51.5 \pm 4 \mathrm{~min}$ vs $83 \pm 7$ $\min , \mathrm{P}<0.05)$. Postoperative mean haemoglobin of patients was no different between the two groups $(9.4 \pm 0.7 \mathrm{~g} / \mathrm{dl}$ vs $9.2 \pm 0.5, \mathrm{P}>0.05)$. The overall cost
\end{abstract}


of management was reduced in the group with tourniquet $(190,680 \pm 1450 \mathrm{~F}$ CFA vs $256,800 \pm 2350$ FCFA; $\mathrm{P}<0.05)$. Conclusion: The use of tourniquet during myomectomies significantly reduces blood loss and the use of blood transfusion. We also obtain the notorious reduction in the use of sutures, the duration of interventions, and the overall cost of care. Thus, we encourage the systematic use of tourniquet during myomectomies by laparotomy.

\section{Keywords}

Tourniquet, Myoma, Myomectomies, Prevention, Haemorrhage, Cost, Brazzaville, Congo

\section{Introduction}

The myomectomy has the particularity of being a haemorrhagic surgical procedure likely to be life-threatening [1]. Also, various means of reducing blood loss during myomectomy, of variable effectiveness were developed preoperatively (agonists gonadotrophin releasing hormone and uterine artery embolization) and intraoperatively (vasoconstrictors, oxytocin, and the withers) [1] [2] [3] [4] [5].

In our developing world context, myomectomy remains a risky surgery regarding the problems associated with the shortage of blood products and the reluctance of certain patients to blood transfusion [6]. The use of the tourniquet or tourniquet as a mechanical means of temporarily interrupting the myometrial blood flow is possible to reduce blood loss and its consequences [6].

Also, this study aims to verify the effectiveness of tourniquet in the prevention of haemorrhage during myomectomies at the University Hospital of Brazzaville.

\section{Patients and Methods}

It was a cross-sectional analytical study, conducted at the University Hospital of Brazzaville from June 1, 2014 to June 31, 2016.

Included were all patients operated for myomectomy at the University Hospital of Brazzaville, randomly matching each case of myomectomy performed using a tourniquet with two cases of myomectomy without tourniquet. On this basis, we counted 50 myomectomies with tourniquet, constituting the first group (study population or case) and 100 myomectomies without tourniquet, constituting the second group (control population).

Patients operated on by myoma outside the University Hospital and secondarily admitted, or cases of localization of myoma exclusively sub serous were not considered.

Operators were obstetrician gynaecologists trained in the practice of myomectomy.

Myomectomies in both groups were systematically performed after transverse cutaneous approach, by anterior incision, followed by enucleation with scissors 
or digitalis. Hysterography was then performed in two planes using the resorbable wire.

As a tourniquet, we used the surgical glove knotted and tightened sufficiently at the level of the isthmus of the uterus (Figure 1) in order to temporarily obtain the occlusion of the uterine arteries and to ensure haemostasis lasting not exceeding one hour.

We analysed for each patient the variables:

- Preoperative: age in years, indication for surgery, haemoglobin in grams per decilitre;

- Inoperative: the type of anaesthesia, the size of the uterus, the number of myomas, the estimated blood loss in millilitre, the number of threads, the duration of intervention in minutes, the transfusion;

- Postoperative: the operative follow-up, the haemoglobin level in grams per decilitre, the hospital stays;

- In relation to the overall cost of care considering drugs, consumables, blood transfusion, and hospitalization costs.

The data collected was analysed using epi data 3.1 software. We performed Chi-2 independence tests to assess the statistical difference between two qualitative variables. The adjusted Chi- 2 test was applied when the expected value in the contingency table was less than $5 \%$. The observed difference between two quantitative variables was verified by applying the t-Student test. The test was significant for a probability less than 0.05 .

\section{Results}

Both groups of patients had identical characteristics with respect to age, preoperative haemoglobin level, and operative indication (Table 1).

Intraoperative parameters have been reported in Table 2. The two groups were comparable in the type of anaesthesia and the surgical procedure performed.

On the other hand, a significant difference was observed in terms of the amount of intraoperative perfusion, blood loss, and use of consumables (sutures and number of compresses).

We recorded more cases of complicated operative follow-up in the group of myomectomies who did not use tourniquet, as shown in Table 3.

The haemoglobin level was similar postoperatively, as well as the duration of hospitalization in both groups. The cost of management was significantly reduced in the myomectomy group with tourniquet.

\section{Discussion}

Our study focused on the use of tourniquet, a haemostatic preventive measure for which few publications are devoted to it in Africa [7]. Indeed, routine tourniquet use is not common practice, as evidenced by studies of myomectomy without tourniquet [8] [9]. 


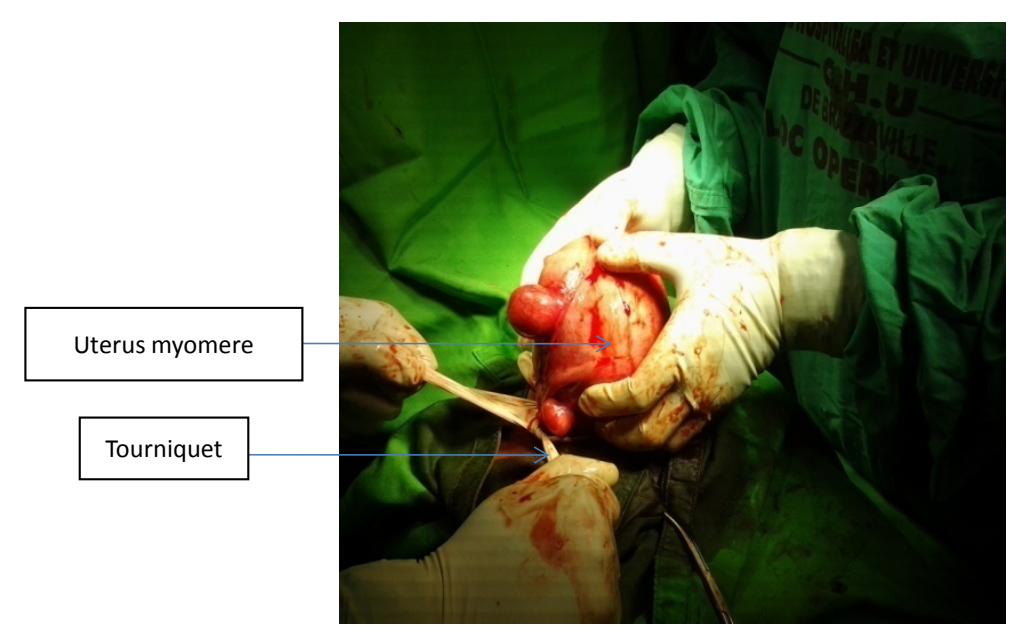

Figure 1. Uterine tourniquet placement during myomectomy.

Table 1. Preoperative characteristics of myomectomies.

\begin{tabular}{cccc}
\hline & Tourniquet & $\begin{array}{c}\text { Without } \\
\text { Tourniquet }\end{array}$ & $\mathrm{P}$ \\
\hline Age years (Mean-Std) & $36.1 \pm 2.2$ & $36.2 \pm 1.9$ & 0.12 \\
Extremes in years & $(26-41)$ & $(28-40)$ & 0.40 \\
Haemoglobin in g/dl (Mean-Std) & $9.03 \pm 1.10$ & $975 \pm 1.29$ & 0.41 \\
Extremes & $(8.73-12.31)$ & $(8.88-11.98)$ & \\
Indications of surgery (\%) & $38(76)$ & $72(72)$ & \\
Menorrhagia & $8(16)$ & $16(16)$ & \\
Masse & $4(8)$ & $12(12)$ & \\
Infertility & &
\end{tabular}

Std: Standard deviation, n: effective, g: gram, dl: decilitre.

Table 2. Preoperative characteristics of myomectomies.

\begin{tabular}{cccc}
\hline & Tourniquet & Without Tourniquet & P \\
\hline Type anaesthesia n ('\%) & & & 0.10 \\
General & $16(32)$ & $30(30)$ & \\
Loco-regional & $34(68)$ & $70(70)$ & \\
Perfusion per operatories & & & 0.000 \\
Mean-Standard deviation & $1250 \pm 94.5$ & $2400.5 \pm 97.6$ & \\
$\quad$ Extremes & $750-2000$ & $2000-3000$ & 0.13 \\
Surgical procedure practiced n ('\%) & & & \\
Single myomectomy & $12(24)$ & $27(27)$ & 0.001 \\
polymyomectomy & $38(76)$ & $73(73)$ & 0.002 \\
Blood loss & & & \\
Mean-Standard deviation & $90.5 \pm 4.6$ & $200.4 \pm 5.6$ & 0.001 \\
$\quad$ extremes & $75-150$ & $185-350$ & \\
Blood transfusion n ('\%) & $4(8)$ & $50(50)$ & 0.05 \\
Number of sutures & $3 \pm 0.2$ & $6 \pm 0.2$ & \\
Mean-Standard deviation & $(2-5)$ & $(5-8)$ & 0.04 \\
$\quad$ extremes & 2 & 4 & \\
Box of compresses & $(1-3)$ & $(3-6)$ & \\
Mean-Standard deviation & & $83 \pm 7$ min & \\
Duration of the intervention & $51.5 \pm 4$ min & $(40-120)$ & \\
Mean-Standard deviation & & & \\
extremes & $(40)$ & &
\end{tabular}


Table 3. Preoperative characteristics of myomectomies.

\begin{tabular}{cccc}
\hline & Tourniquet & Without Tourniquet & $\mathrm{P}$ \\
\hline Operative suites & $50(100)$ & $92(92)$ & 0.25 \\
simple & 0 & $8(8)$ & 1.02 \\
complicated & $9.4 \pm 0.7$ & $9.2 \pm 0.5$ & 1.49 \\
Haemoglobin in g/dl (Mean-Std) & $(8.01-10.21)$ & $(7.13-10.37)$ & 0.04 \\
extremes & $4.5 \pm 0.6$ days & $5 \pm 0.8$ days & \\
Duration of hospitalisation & $(3-5)$ & $(3-6)$ & \\
Mean Standard Deviation & $190,680 \pm 1450$ & $256,800 \pm 2350$ & \\
extremes & $151,000-200,000$ & $181,000-286,000$ & \\
Cost of care & & & \\
Mean-Standard deviation & & & \\
extremes & & & \\
\hline
\end{tabular}

*Fever: 6 cases; Urinary infection: 2 cases.

We used the surgical glove as a means of tourniquet. This choice was deliberate, related to the cost, accessibility of this device in our environment. Other teams use the Folley probe [6], the elastic tourniquet [10], the Shirodkar clamp [11] or the resorbable wire [12].

The use of the tourniquet during myomectomies has made it possible to control haemostasis; significantly reducing the number of sutures and compresses. In addition, this also allowed us to significantly reduce blood loss that did not exceed a Mean of $100 \mathrm{ml}$; unlike Pither in Libreville, Gabon [6] who, despite the use of tourniquet, found $27 \%$ of cases of intraoperative bleeding greater than 500 $\mathrm{ml}$ without any real explanation.

Notwithstanding the context of polymyomectomies performed in both groups, blood transfusion was significantly reduced in the tourniquet group. Ikechebelu [7] reveals that the reduction of transfusion in the group with tourniquet concerns both the number of transfused patients and the volume of blood.

Like Flether [13], we did not observe thromboembolic, necrotic, and ischemic complications during continuous tourniquet tightening. Similarly, we have not noticed the hypotension related to the secretion of toxic substances as described previously by Rubin [10], during the continuous tightening of the tourniquet.

\section{Conclusion}

The use of tourniquet during myomectomies significantly reduces blood loss, and therefore the use of blood transfusion. We also obtain the notorious reduction in the use of sutures, the duration of interventions, and the overall cost of care. Therefore, we encourage the systematic use of tourniquet during myomectomies by laparotomy.

\section{Conflict of Interest}

No conflict of interest, regarding this article, is to be feared from us.

\section{References}

[1] Davitian, C., Ducarme, G., Rodriques, A.B., Tigaizin, A., Duaphin, H. and Benchi- 
mol, M. (2005) Myomectomie: Prévention de l'hémorragie. Gynécologie Encyclopédie Médico-chirurgicale, 41-666.

[2] Fedele, L., Vercellini, P. and Dorta, M. (1990) Treatment with GnRH Agonist before Myomectomy and the Risk of Short Term Myoma Recurrence. British Journal of Obstetrics and Gynaecology, 97, 363-366. https://doi.org/10.1111/j.1471-0528.1990.tb01824.x

[3] Vercellini, P., Trespie, L. and Crosignani, P.G. (2003) Gonagotrophin Releasing Hormon Agonist Treatment before Abdominal Myomectomy: A Controlled Trial. Fertility and Sterility, 79, 1390-1395. https://doi.org/10.1016/S0015-0282(03)00362-5

[4] Ravina, J.H., Herbreteau, D. and Merland, J.J. (1995) Arterial Embolisation to Treat Uterine Myomata. Lancet, 346, 671-672. https://doi.org/10.1016/S0140-6736(95)92282-2

[5] Bourret, J.M. (1999) Place de l'embolisation dans la pathologie myomateuse. Journal de Gynécologie Obstétrique et Biologie de la Reproduction, 28, 753-760.

[6] Pither, S., Mayi Songa, S., Dankoro, A., OgowerIgumu, N. and Mounanga, M. (2007) Pathlogie myomateuse à Libreville: Palce du traitement conservateur par voie abdominale à propos d'une série de 127 cas. Medecine d Afrique Noire, 54, 263-267.

[7] Ikechebelu, J.I., Ezeama, C.O. and Obiechina, N.J.A. (2010) The Use of Tourniquet to Reduce Blood Loss at Myomectomy. Nigerian Journal of Clinical Practice, 13, 154-158.

[8] Dia, A., Beye, S.B., Dangou, J.M., Dieng, M., Wotogaye, G. and Toure, C.T. (2003) Les fibromes utérins à la clinique chirurgicale de Dakar. Dakar Médical, 48, 72-76.

[9] AdamaHondegla, A., Modji, S., Aboubakari, A., Wonegou, K. and Akpadza, K. (2012) Aspects épidémiologiques et chirurgicaux de fibromes utérins opérés à l'hopital du district $\mathrm{N}^{\circ}$ III de Lomé. Journal de la Recherche Scientifique de I'Université de Lomé (Togo), Série D, 14, 131-137.

[10] Rubin, I. (1942) Progress in Myomectomy. American Journal of Obstetrics \& Gynecology, 44, 196-212. https://doi.org/10.1016/S0002-9378(42)90588-X

[11] Bonney, V. (1931) The Technique and Results of Myomectomy. Lancet, 1, 171-177. https://doi.org/10.1016/S0140-6736(00)40479-4

[12] Liu, W.M., Tzeng, C.R. and Wang, P.H. (2004) Combining the Uterine Depletion Procedure and Myomectomy May Useful for Treating Symptomatic Fibroids. Fertility and Sterility, 82, 205-210. https://doi.org/10.1016/j.fertnstert.2004.01.026

[13] Flether, H., Frederick, J., Hardie, M. and Simeon, D. (1996) A Randomized Comparison of Vasopressin and Tourniquet as Hemostatie Agent during Myomectomy. Obstetrics \& Gynecology, 87, 1014-1018. https://doi.org/10.1016/0029-7844(96)00071-3 